\title{
Nicotinamide and NAFLD: Is There Nothing New Under the Sun?
}

\author{
Maria Guarino ${ }^{1,2}$ and Jean-François Dufour 1,3,* \\ 1 Hepatology, Department for BioMedical Research, University of Bern, 3008 Bern, Switzerland \\ 2 Gastroenterology, Department of Clinical Medicine and Surgery, University of Naples Federico II, \\ 80131 Naples, Italy \\ 3 University Clinic of Visceral Surgery and Medicine, Inselspital Bern, 3008 Bern, Switzerland \\ * Correspondence: jean-francois.dufour@dbmr.unibe.ch
}

Received: 8 August 2019; Accepted: 6 September 2019; Published: 10 September 2019

\begin{abstract}
Nicotinamide adenine dinucleotide (NAD) has a critical role in cellular metabolism and energy homeostasis. Its importance has been established early with the discovery of NAD's therapeutic role for pellagra. This review addresses some of the recent findings on NAD physiopathology and their effects on nonalcoholic fatty liver disease (NAFLD) pathogenesis, which need to be considered in the search for a better therapeutic approach. Reduced NAD concentrations contribute to the dysmetabolic imbalance and consequently to the pathogenesis of NAFLD. In this perspective, the dietary supplementation or the pharmacological modulation of NAD levels appear to be an attractive strategy. These reviewed studies open the doors to growing interest in NAD metabolism for NAFLD diagnosis, prevention, and treatment. Future rigorous clinical studies in humans will be necessary to validate these preliminary but promising results.
\end{abstract}

Keywords: nicotinamide; NAFLD; steatosis

\section{Introduction}

The global diabesity (diabetes and obesity) [1] epidemic has dramatically increased the prevalence of nonalcoholic fatty liver disease (NAFLD), such that it is the most frequent cause of chronic liver disease. NAFLD is considered to be the liver manifestation of the metabolic syndrome, because of its frequent association with dyslipidemia, cardiovascular disease, obstructive sleep apnea, vitamin D deficiency, and other components of the metabolic syndrome, and insulin resistance is central to its pathogenesis [2,3].

Liver steatosis is the hallmark histologic feature of NAFLD, and it is the result of triglyceride accumulation in the hepatocytes cytoplasm. Liver lipid accumulation arises from an imbalance between lipid accumulation and removal, which is linked to increased liver lipogenesis, increased lipid uptake, and/or reduced triglyceride export or $\beta$-oxidation [4,5]. Liver secretion of triglycerides as very low-density lipoprotein (VLDL) particles for delivery to peripheral tissues is a crucial pathway for the mobilization of hepatic fat. Defects in VLDL processing are directly linked to hepatic steatosis. Jiang et al. showed that non-alcoholic steatohepatitis (NASH) was related to an increment in VLDL particle size, while hepatic fibrosis was related to a reduction in the concentration of small VLDL particles [6]. Moreover, there is a relationship between choline deficiency and accumulation of liver lipid, which is why choline-deficient diets are often used to induce NAFLD in animal models. Within hepatocytes, choline may be oxidized for phosphatidylcholine synthesis. Liver phosphatidylcholine is used to build the monolayers of VLDL, and its deficiency increases de novo hepatic lipogenesis [7].

The present model for NAFLD pathophysiology, called "the multiple-hit hypothesis", defines NAFLD as the manifestation of environmental and genetic factors, including the dysfunction of 
different organs and organelles, together with the intricate interaction between hepatocytes and other cells (such as stellate cells and Kupffer) in the liver [8]. Additionally, the liver is a hub for several metabolic pathways defining NAFLD as a multistep, progressive systemic disease.

\section{NAD: Behind Its Metabolism}

Nicotinamide adenine dinucleotide (NAD) is a hydride acceptor producing the reduced NADH, as well as the derivate phosphorylated dinucleotide pair NADP/NADPH, which is required for many cellular biosynthetic pathways and for protecting cells from reactive oxygen species (ROS). The keystone function of NAD is to facilitate hydrogen transfer in metabolic pathways as enzyme cofactors dealing with hydrogen transfer in reductive or oxidative metabolic reaction. So, it plays a central role in basic energy metabolism such as assisting with mitochondrial electron transport, glycolysis, the oxidation of fatty acids and amino acids in mitochondria, and the citric acid cycle. NAD is also a substrate for signaling enzymes such as poly (ADP ribose) polymerase (PARP), sirtuins (SIRTs), and ADP ribosyl transferases, called "NAD consumers" [9] (Figure 1). For example, it is involved in repairing and maintaining genomic integrity, thanks to PARP, which transfers ADP-ribose from NAD to itself, histones, and other proteins at sites of DNA damage.

De novo synthesis

\section{Tryptophan}

Quinolonicacid

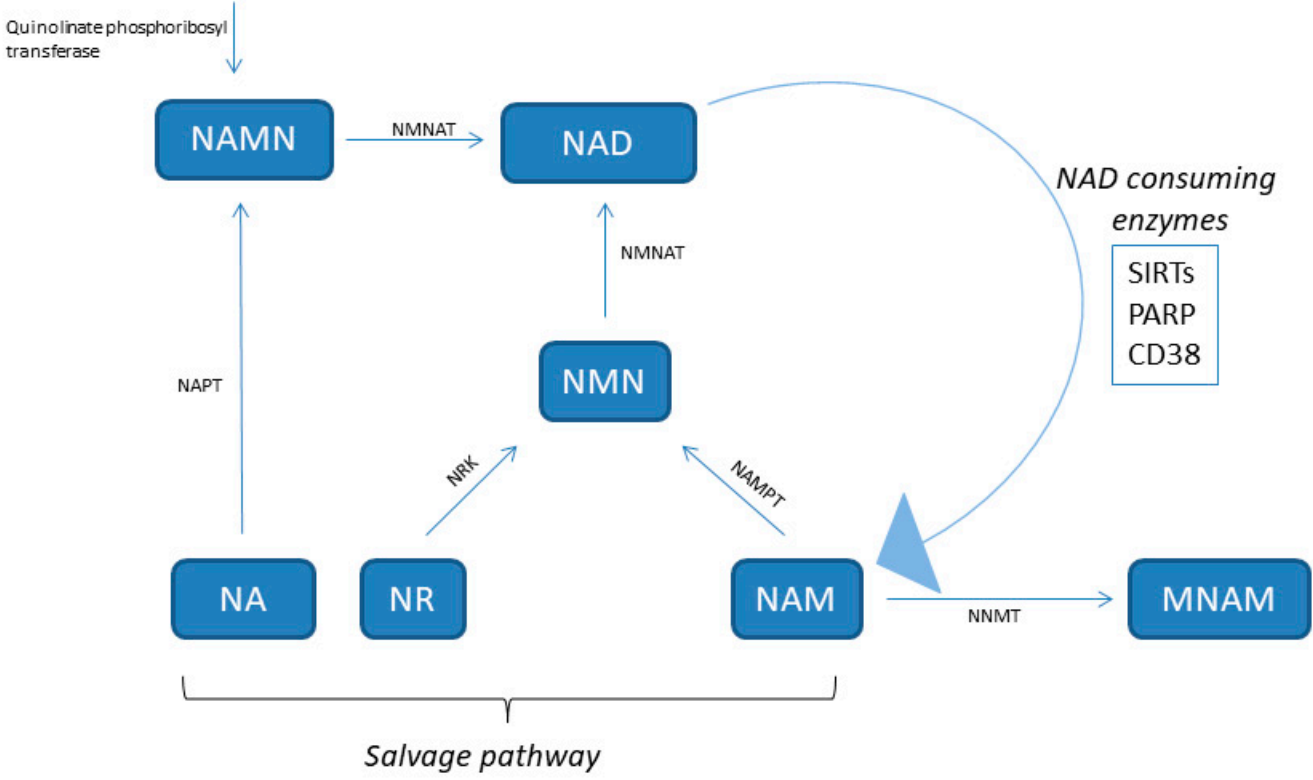

Figure 1. NAD synthesis pathways. NA, nicotinic acid; NAD, nicotinamide adenine dinucleotide; NAM, nicotinamide; NAMN, nicotinic acid mononucleotide; NAPT, nicotinic acid phosphoribosyltransferase; NMN, nicotinamide mononucleotide; NMNAT, nicotinamide nucleotide adenylyltransferase; NR, nicotinamide riboside; NRK, NR kinase; NNMT, nicotinamide-N-methyltransferase; PARP, poly (ADP ribose) polymerase; NNMT, nicotinamide N-methyltransferase; NAMPT, nicotinamide phosphoribosyltransferase; SIRT, sirtuin.

The cellular NAD pool is created by a balance between the activity of NAD-consuming and synthesizing enzymes [10-12]. NAD concentrations display the cell energy state and are modulated by physiological processes. In fact, during fasting, caloric restriction, and exercise, NAD levels increase. Conversely, caloric excess and aging diminish NAD levels [13]. 
NAD is synthesized from four distinct biosynthetic precursors in two different pathways (Figure 1). De novo synthesis (the deamidated pathway) uses as precursor the dietary amino acid tryptophan, which is metabolized to create biosynthetic intermediates. In particular, the creation of unstable $\alpha$-amino- $\beta$-carboxymuconate- $\varepsilon$-semialdehyde (ACMS) forms a branching point of the deaminated pathway. The ACMS is subjected to both non-enzymatic cyclization or complete enzymatic oxidation to quinolinic acid, and this is the first limiting step [14]. The second limiting mechanism involves the catalytic conversion of quinolinic acid to nicotinic acid mononucleotide (NAMN) by quinolinate phosphoribosyl transferase. Next, NAMN is transformed into NAD by the nicotinamide mononucleotide adenylyltransferase (NMNAT) enzyme. This pathway is recognized as the minor contributor to the total NAD pool [14].

Dietary vitamin B3 compounds, including nicotinic acid (NA), also known as niacin, NAM, and nicotinamide riboside (NR), supply as NAD biosynthetic precursors and are rescued from the diet (the amidated pathway) for generating cellular NAD. This salvage pathway is the most relevant for NAD homeostasis [15]. NA is converted to NAMN by nicotinic acid phosphoribosyltransferase (NAPT), which is afterward converted to NAD by NMNAT. The NAM and NR are transformed into NMN by nicotinamide phosphoribosyltransferase (NAMPT) and NR kinase (NRK) enzymes, respectively. Finally, NMN is enzymatically transformed into NAD by NMNAT [15].

NAMPT, also known with the name visfatin, is a highly conserved protein with cytokine functions, which is expressed in almost all tissues and cells (Figure 1) [16]. In particular, it is an essential regulator of the intracellular NAD pool by catalyzing the formation of nicotinamide mononucleotide (NMN) from nicotinamide and 5'-phosphoribosyl-1-pyrophosphate, which is the limiting step in the NAD salvage pathway [17]. NAMPT has both intracellular and extracellular forms in mammals. The extracellular NAMPT (eNAMPT) is secreted from adipocytes [18], hepatocytes [19], and leucocytes [20] and circulates in the blood where, additionally to its enzymatic function, it has also cytokine-like actions $[16,21,22]$. In virtue of its NAD biosynthetic activity, intracellular NAMPT (iNAMPT) controls the activity of NAD-dependent and consuming enzymes, such as SIRTs [23], the NADase CD38 (a cyclic ADP-ribose synthesis) [24], and PARPs [25], by which it controls mitochondrial biogenesis, cellular metabolism [26], and adaptive responses to oxidative, inflammatory, genotoxic, and proteotoxic stress [27]. Genotoxic stress and nutrient deprivation activate NAMPT, which protects cells from these stresses through the maintenance of the mitochondrial NAD level [23].

The NAD levels are also regulated by the cytosolic enzyme nicotinamide-N-methyltransferase (NNMT), which methylates nicotinamide to produce N1-methyl nicotinamide (MNAM) toward the universal methyl donor S-adenosylmethionine as a methyl donor (Figure 1). NNMT is mainly expressed in the liver, but also in other organs such as muscle, adipose tissue, and heart. An increase of NNMT expression has been observed in obesity and diabetes [28-30].

SIRTs are NAD-dependent deacylases [31]. SIRTs have key roles in response to environmental and nutritional perturbations, such as DNA damage, oxidative stress, and fasting. For this reason, SIRTs have to be considered as nutritional sensors that operate in regulating glucose and lipid homeostasis, inflammatory responses, and cell death [23,32-34]. Additionally, SIRTs influence cells' metabolism through the regulation of the circadian clock machinery with the deacetylation of central clock components in the liver [35,36]. Accordingly, NAD synthesis is controlled by the circadian machinery to furnish a crucial link from the clock oscillator to metabolic pathways [37]. NAD is synthesized with circadian oscillations, leading to a circadian schedule of SIRT activation and mitochondrial metabolism, such as the oxidation of fatty acids [38]. SIRTs' activity is dependent on its cofactor NAD and it is sensitive to the cellular NAD levels [39], designating NAD as a rate-limiting substrate for their reactions $[32,40,41]$. As NAM is the product of SIRT-catalyzed deacetylation reactions, high levels of NAM have been used as a SIRTs inhibitor [42]. This drives speculation that enzymes involved in NAD synthesis could control SIRTs' activity. For example, an increment in NAD was proposed by Lin et al. to mediate the health span and extension of life by dietary restriction [43], and recently, 
studies demonstrated that the activity of SIRTs declines with aging by a systemic reduction in NAD levels $[44,45]$.

\section{NAD Involvement in NAFLD Pathogenesis}

In the last years, an emerging role of NAD metabolism in protection against NAFLD stimulated a growing interest. Von Shönfels et al. performed a small-molecule metabolite screen of human hepatic tissue to find metabolic markers related to NASH histology. According to its concentration in liver tissue, they suggested a protective effect of NA, which was subsequently verified in a nutritional animal model of NAFLD showing a marked effect on steatosis and transaminases levels with NA supplementation [46]. NAD deficiency decreases the oxidation of fatty acids, promoting steatosis [47]. Usually, the triglycerides are broken down into glycerol and fatty acids, so they can enter into the mitochondria and proceed on with fatty acid oxidation. Fatty acids shift in this pathway as Coenzyme A (CoA) derivatives utilizing NAD. The acetyl groups created by the $\beta$-oxidation of the fatty acid take part in the activity of the Krebs cycle, causing the formation of NADH. The reduced coenzyme (NADH) is oxidized by leaving the protons and electrons to oxygen in the mitochondria to synthesize ATP in the electron transport system [48]. So, NAD deficiency causes a reduction of $\beta$-oxidation, and consequently the accumulation of triglycerides in the hepatocytes (steatosis).

The control of rate-limiting enzymes of NAD biosynthesis avoids the negative effects of high-fat diet (HFD) and keeps up insulin sensitivity and glucose homeostasis. Penke et al. [49] reported increased hepatic NAD levels in mice under HFD thanks to increased NAMPT expression. So, it seems that NAD deficiency is a crucial risk factor for NAFLD resulting from having compromised the NAMPT-controlled NAD salvage pathway in liver [50]. Plasma levels of eNAMPT may be closely linked to NAFLD, obesity, diabetes, and atherosclerosis [51-54]. Moreover, decreased NAMPT expression in NAMPT +/- mice, which reduced circulating NMN levels and decreased NAD levels in brown adipose tissue, impaired glucose-stimulated insulin secretion [22]. This event can be rescued by NMN supplementation, suggesting that the maintenance of NAD concentrations is critical for pancreatic function [22].

The mechanisms of NAMPT protecting the liver from HFD are depicted in Figure 2. NAMPT induces the production of NAD by activating the NAD salvage pathway, and consecutively, the augmented NAD (as a substrate) activates the SIRT 1 and 3 signaling pathways, alleviating HFD-induced hepatic steatosis. De novo lipogenesis (DNL) is known to be high in individuals with NAFLD, and provides about $26 \%$ of hepatic lipids $[55,56]$. The NAMPT is critical for the formation of acetyl-CoA and for the increase of fatty acid oxidation by providing NAD for SIRT3 with the activation of acetyl-CoA synthetase (ACS) [57]. At the same time, the activation of SIRT1 by NAMPT promotes the deacetylation of sterol regulatory element-binding protein 1 (SREBP1), which inhibits SREBP1 activity, resulting in the lower expression of lipogenesis genes, including fatty acid synthase (FAS) and acetyl-CoA carboxylase (ACC). Additionally, SIRT 1 directly activates AMP-activated protein kinase (AMPK), which further inhibits SREBP1 activity. All together, these results show that NAMPT modulates processes involved in NAFLD pathogenesis (such as de novo lipogenesis and fatty acid oxidation). Accordingly, Zhou et al. showed that dominant negative-NAMPT transgenic mice, under normal chow, display systemic NAD decrease and had a moderate NASH phenotype, with enhanced oxidative stress, lipid accumulation, impaired insulin sensitivity, and triggered inflammation in liver. These features deteriorate further under HFD [50]. 


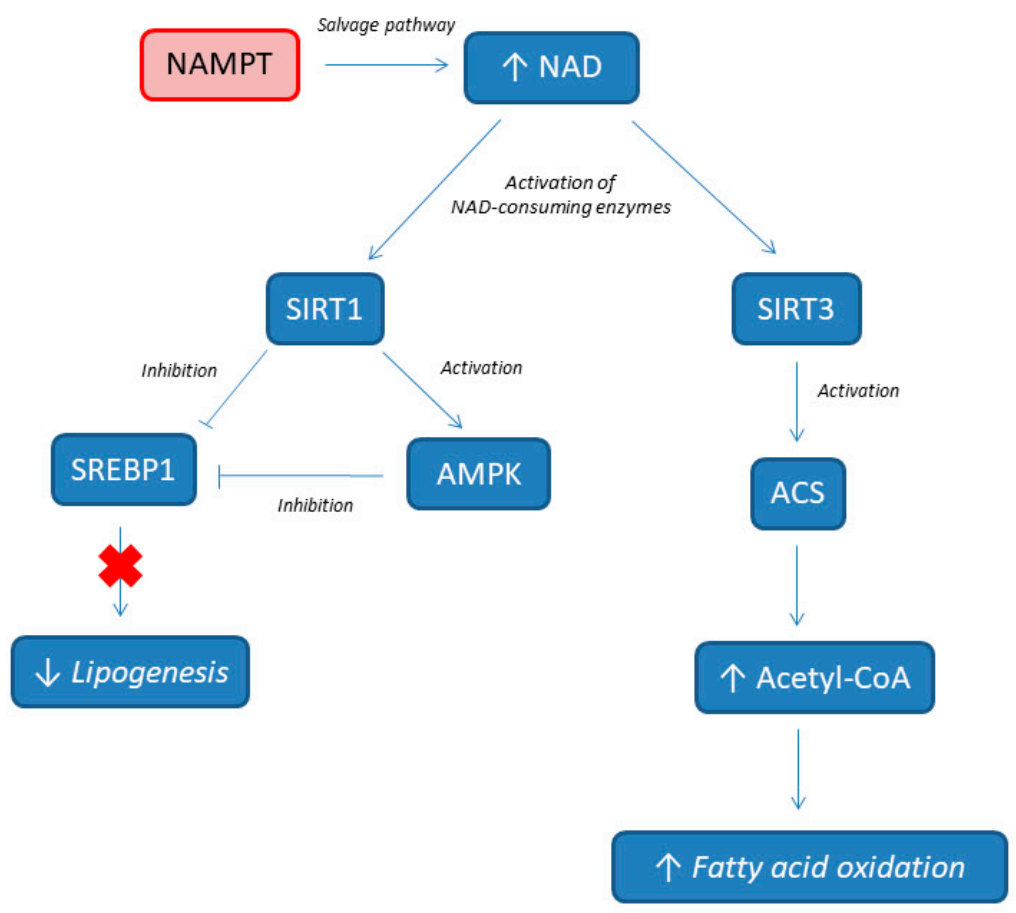

Figure 2. NAMPT involvement in lipids metabolism. NAMPT, nicotinamide phosphoribosyltransferase; NAD, nicotinamide adenine dinucleotide; ACS, acetyl-CoA synthetase; AMPK, AMP-activated protein kinase; SIRT, sirtuin; SREBP1, sterol regulatory element-binding protein 1.

NNMT has also been associated to the development of diabetes, obesity, and metabolic syndrome [28-30]. An increase of NNMT expression has been observed in obesity and diabetes [28-30], probably because NNMT controls lipid, cholesterol, and glucose metabolism by stabilizing SIRTs [58]. In humans, adipose tissue NNMT expression and its product MNAM correlate positively with insulin resistance. Kannt et al. [29] showed an increased expression of NNMT in the adipose tissue of diabetic patients according to the insulin resistance severity, suggesting that NNMT could be a "bad actor" limiting fuel oxidation and promoting fat storage. NNMT protein levels are upregulated in the liver and adipose tissue of mouse models of insulin resistance and obesity, and NNMT knockdown has a protective effect against the metabolic consequences of HFD [28], suggesting that NNMT may have a critical role in NAFLD pathogenesis. The dietary regulation of liver NNMT expression, the site of its major expression, shows some interesting patterns. The ketogenic diet suppresses liver NNMT expression, contributing to the increased liver and serum cholesterol levels in this model [59]. Conversely, caloric restriction increased NNMT liver expression, promoting SIRT1 protein stability, which mediates several metabolic effects of caloric restriction [60]. Liver NNMT expression inversely correlates with serum triglycerides (TGs), cholesterol, and free fatty acid levels, suggesting that increased liver NNMT expression is associated with a better metabolic profile, contrary to its expression in adipose tissue [28,29]. Furthermore, a genome-wide association study showed significant associations between the risk of developing NASH and a specific single-nucleotide polymorphisms (SNPs) in the NNMT gene (rs694539) [61]: in this case, subjects with the AA genotype showed a statistically significant increased NASH risk, while the GG genotype seemed to be protective. Similarly, Hasan et al. showed that the AA genotype correlates with the degree of steatosis as detected by the controlled attenuation parameter, even if it does not correlate with the degree of fibrosis detected by FibroScan [62].

\section{NAD as Biomarker for NAFLD Diagnosis}

The identification of non-invasive biomarkers has become a major focus of interest in NAFLD. Since the diagnosis of NASH is still a histological one, the dramatic increase in the prevalence of 
NAFLD and its severity spectrum mean that liver biopsy is not feasible for all patients. Current plasma biomarkers include predictive models for diagnosing or grading steatosis (such as the fatty liver index) or staging fibrosis (such as the NAFLD fibrosis score), and other ones specific to NAFLD (such as the BARD and NAFLD fibrosis scores), even if some have been initially developed in a hepatitis $C$ setting (AST/ALT ratio, APRI, FIB-4) [63].

Several studies evaluated the relationship between NAD metabolism and NAFLD [29,64-68] (Table 1). Human studies investigated how plasma and liver NAMPT protein levels are affected in subjects with steatosis and NAFLD [64-68]. Gaddipati et al. [64] showed that a significant reduction in the NAMPT levels of the visceral adipose tissue is associated to degree of steatosis in NAFLD patients. Similarly, Amirkalali et al. [68] showed that higher serum NAMPT is associated with lower liver DNL in female subjects (probably associated with a higher adipose tissue DNL according to the higher fat mass), while the only significant association in male subjects was between serum NAMPT and liver fat content, probably for the inflammatory role of NAMPT. Thus, the plasma NAMPT levels could have a different meaning for each sex because of the opposing effects of liver and adipose tissue DNL on NAFLD pathogenesis. Conversely, Kannt et al. [29] showed that NNMT mRNA in adipose tissue and 1-methylnicotinamide serum concentrations are higher in patients with insulin resistance and correlate with insulin resistance severity. An additional interesting result is that improvements of insulin sensitivity obtained with exercise and bariatric surgery are associated with a reduction of NNMT expression in adipose tissue and of 1-methylnicotinamide serum levels [29].

\section{NAD Supplementation for NAFLD Prevention}

The evidence for using dietary supplementation to prevent chronic disease is a longstanding issue of debate. Several evidences are emerging to support the hypothesis that supplementation with NAD precursors could protect against metabolic imbalance and liver steatosis (Table 2) [12,49,69-71]. A supplementation study with NMN showed its property to restore NAD levels either in nuclear and mitochondrial cells compartments and to prevent diet-induced and age-induced diabetes in C57BL/6 mice [12]. Tao et al. showed that NAMPT gives resistance to hepatic steatosis through NAD synthesis [69], and NR supplementation gives protection against steatosis in mice under high-fat/high-sucrose diet [70,71]. NAM supplementation protects hepatocytes from palmitate-induced cell death, and autophagy induction contributes to the anti-lipotoxic property of NAM through SIRT1 activation in hepatocytes. Additionally, NAM prevents hepatic alterations in glucose-6-phosphate dehydrogenase and the redox state, and attenuates increased serum FFA, oxidative stress, inflammation, and hepatic damage in high fructose or high glucose consumption-induced liver steatosis in rats [72]. Lastly, Komatsu et al. showed that NNMT and NAM supplementation causes liver steatosis and fibrosis, although increased lipid metabolism and decreased adiposity. NNMT overexpression induces genes for liver steatosis and fibrosis by decreasing tissue NAD content and methylation pool, suggesting that NNMT connects NAD and methionine metabolism and causes NAFLD progression [73]. Thus, NAD supplementation may represent a preventive treatment for metabolic dysfunctions such as diabetes, and NAFLD spectrum disease, from steatosis to NASH.

\section{NAD Supplementation for NAFLD Treatment}

The relevance of dietary NAD precursors in health is well known, thanks to the historical use of NA and NAM in the treatment of dietary tryptophan deficits (pellagra) and hyperlipidemia, although high-dose NA use is limited by painful flushing, while high-dose NAM is hepatotoxic [74,75]. In fact, the use of NA is associated with a flush of face and chest and a sensation of warmth or burning. NA causes flushing principally by releasing prostaglandins D2 and E2 from skin cells, which afterwards dilates skin arterioles [76,77]. The precursors NA, NMN, and NR, but also PARP or CD38 inhibitors, rise NAD levels in different mice cells and tissues [12,13,70]. Boosting NAD concentrations can be therapeutic in metabolic diseases such as diabetes [12,53] and NAFLD [70], and potentially protects against obesity [51] and age-related disorders (Table 3). 
Due to its ability to increase NAD synthesis without inducing side effects [44,70], NR has been used in mice to increase NAD metabolism and improve health in models of metabolic stress, showing that NR abolishes DNA damage in HFD-fed mice [70,78]. Canto et al. [70] treated mice with NR $(400 \mathrm{mg} / \mathrm{kg}$ animal weight per day), demonstrating an increase of NAD levels in muscle and liver. Mice under HFD were protected from body weight increase and showed an improvement of mitochondrial function and fatty acids oxidation as a fuel source. In accordance with increases in tissue NAD levels, SIRT1 and SIRT3 were upregulated [70]. NR also ameliorated insulin sensitivity in weight-matched mice [70]. Similarly, Zhou et al. [50] demonstrated that the oral administration of NR corrects NAFLD phenotypes induced by NAD deficiency alone or combined with HFD. Trammell et al. [79] performed a clinical study enrolling 12 healthy subjects receiving three single doses of NR, demonstrating that NR supplementation safely induces NAD metabolism at all doses. They also demonstrated that NR is more orally bioavailable than NAM, which is more orally bioavailable than NA. The capability of NR to increase ADPR is threefold higher than NAM. This validates NR as the preferred NAD precursor vitamin for boosting NAD and NAD-consuming activities in liver. No dose-dependent side effects of NR have been reported, contrary to high-dose NAM, which may lead to liver damage [15]. Shi et al. [80] carried out a dose-response dietary intervention mice study using a wide range of NR (from 5 to $900 \mathrm{mg}$ NR per $\mathrm{kg}$ of an obesogenic diet), concluding that $30 \mathrm{mg} / \mathrm{kg}$ diet constitutes the best concentration to reinforce metabolic health. These studies showed the powerful biological effects of NR in mitigating the negative consequences of HFDs $[70,71,81,82]$, suggesting that NAD substrates supplementation may be a promising therapeutic strategy for preventing and treating NAFLD/NASH.

Another possibility to modulate NAD levels consists of using NMN. Supplementation with NMN, an enzymatic product of NAMPT, improves diabetes $[12,13]$ and other damages such as vascular dysfunction, oxidative stress [83], and cognitive impairment [84]. Yoshino et al. demonstrated that increasing NAD biosynthesis by the intraperitoneal injection of NMN improves glucose homeostasis in obese mice, and that NAMPT activity is altered by HFD and can cause diabetes [12]. Similarly, supplementation with MNAM significantly reduces hepatic cholesterol and triglycerides concentrations, by suppressing fatty acid and cholesterol synthesis and the expression of lipogenic and cholesterol synthesis genes [58]. MNAM supplementation produces a selective reduction in larger lipoprotein particles but not high-density lipoprotein, suggesting that MNAM or its derivatives could be used to reduce low-density lipoprotein levels [58].

Another attractive angle to modulate NAD levels consists in targeting the activity of NAD-consuming enzymes, such as CD38 [10] and PARPs [11]. Several studies showed that CD38 knockout $(\mathrm{KO})$ mice have higher NAD levels than Wild-type (WT) animals, and are protected against obesity and metabolic syndrome $[10,85]$. The treatment of obese mice with CD38 inhibitors augments intracellular NAD concentrations and improves glucose and lipid homeostasis [86]. Increased PARP activity causes an elevated consumption of cellular NAD, which is associated to increased ATP consumption, compromising energy balance and facilitating cell death [87]. Upon persistent PARP activation, decreased mitochondrial ATP production inhibits NAD re-synthesis, creating a feed-forward loop in ATP-consuming processes, and resulting in metabolic catastrophe and cell death. PARP inhibition causes an increase in NAD levels. Rucaparib (a PARP inhibitor) significantly increases hepatic NAD levels, as previously described with NAM treatment [88], while in PARP1 KO liver, NAD levels were similar to those in treated PARP1 WT liver. So, CD38 and PARP inhibition combined with NAD precursors may be an intriguing therapeutic perspective for NAFLD [13].

Finally, Katsiuba et al. presented an additional mechanism for increasing NAD levels toward the inhibition of the ACMS decarboxylase with a selective inhibitor recently developed, TES-991. ACMS decarboxylase inhibition in a mouse model of diet-induced NAFLD increased levels of NAD and the activation of SIRT1 with improvement of the NAFLD phenotype, without systemic side effects [14]. 
Table 1. NAD as biomarker for NAFLD diagnosis.

\begin{tabular}{|c|c|c|c|c|}
\hline Biomarker & Study Design & Analyzed Tissue & Results & Ref. \\
\hline NAMPT & $\begin{array}{l}\text { 77 NAFLD patients vs. } 38 \text { control patients } \\
\text { (all undergoing diagnostic laparoscopy) }\end{array}$ & $\begin{array}{l}\text { Visceral adipose tissue } \\
\text { (VAT) }\end{array}$ & $\begin{array}{l}\text { Reduction of NAMPT levels in VAT } \\
\text { according to the degree of steatosis }\end{array}$ & Gaddipati et al. [64] \\
\hline NAMPT & $\begin{array}{l}69 \text { obese women with NAFLD vs. } 19 \\
\text { obese women vs. } 38 \text { healthy women }\end{array}$ & Liver tissue and serum & $\begin{array}{l}\text { Serum NAMPT and its liver expression are } \\
\text { higher in obese women with NAFLD, } \\
\text { irrespective of the presence of diabetes }\end{array}$ & Auguet et al. [65] \\
\hline NAMPT & $\begin{array}{l}58 \text { NAFLD patients vs. } 27 \text { healthy } \\
\text { controls }\end{array}$ & Liver tissue and serum & $\begin{array}{l}\text { NAFLD patients had decreased NAMPT } \\
\text { expression both in serum and in liver } \\
\text { tissue, with no difference between simple } \\
\text { steatosis and NASH }\end{array}$ & Dahl et al. [52] \\
\hline NAMPT & 40 severely obese patients with NAFLD & Liver tissue & $\begin{array}{l}\text { Positive association between NAMPT } \\
\text { expression and the fibrosis stage in NAFLD }\end{array}$ & Kukla et al. [67] \\
\hline NAMPT & 62 NAFLD patients (32 males, 30 females) & Serum & $\begin{array}{l}\text { Higher serum NAMPT in women was } \\
\text { associated with a lower hepatic DNL index, } \\
\text { while in men, it was associated with higher } \\
\text { hepatic fat, and had no association with the } \\
\text { DNL index }\end{array}$ & Amirkalali et al. [68] \\
\hline
\end{tabular}

NAMPT, nicotinamide phosphoribosyltransferase; NNMT, nicotinamide-N-methyltransferase. 
Table 2. NAD supplementation for NAFLD prevention.

\begin{tabular}{|c|c|c|c|}
\hline Preventive Supplementation & Study Design & Results & Ref. \\
\hline NMN & C57BL/6, HFD vs. control diet & $\begin{array}{c}\text { NMN ameliorates glucose intolerance by restoring NAD levels, enhances } \\
\text { hepatic insulin sensitivity, and restores gene expression related to } \\
\text { oxidative stress, inflammatory response, and circadian rhythm, partly } \\
\text { through SIRT1 activation. }\end{array}$ & $\begin{array}{c}\text { Yoshino et al. } \\
\text { [12] }\end{array}$ \\
\hline Nicotinamide & $\begin{array}{l}\text { HepG2 cells and alpha mouse liver } \\
\text { (AML)-12 hepatocyte transfected with } \\
\text { human SIRT1 siRNA under } \\
\text { palmitate-elicited hepatotoxicity }\end{array}$ & $\begin{array}{l}\text { Nicotinamide supplementation protects hepatocytes against } \\
\text { palmitate-induced cell death. SIRT1 inhibition abrogates the nicotinamide } \\
\text { anti-lipotoxic effect. }\end{array}$ & Shen et al. [42] \\
\hline NR & $\begin{array}{l}\text { C57Bl/6J, HFD vs. control diet; murine } \\
\text { C2C12 myoblasts, murine Hepa1.6, and } \\
\text { human HEK293T cells, with or without } \\
\text { deletion of the SIRT3 gene }\end{array}$ & $\begin{array}{l}\text { NR prevents diet-induced obesity by enhancing energy expenditure, } \\
\text { reducing cholesterol levels, and increasing intracellular and mitochondrial } \\
\text { NAD content both in cell and in vivo experiments. NR enhances SIRT1 } \\
\text { and SIRT3 activity and energy expenditure, and ameliorates the oxidative } \\
\text { performance of skeletal muscle and brown adipose tissue. }\end{array}$ & Canto et al. [70] \\
\hline NR & $\begin{array}{l}\text { C57BL/6J mice, high-fat and high-sucrose } \\
\text { diet vs. control diet; primary hepatocytes } \\
\text { from SIRT1 floxed or SIRT3 floxed mice }\end{array}$ & $\begin{array}{l}\text { NR prevents NAFLD by inducing a sirtuin-dependent mitochondrial } \\
\text { unfolded protein response, triggering an adaptive mitohormetic pathway } \\
\text { to increase hepatic } \beta \text {-oxidation and mitochondrial complex content and } \\
\text { activity. }\end{array}$ & $\begin{array}{c}\text { Gariani et al. } \\
\text { [71] }\end{array}$ \\
\hline NAM & $\begin{array}{l}\text { Male Sprague-Dawley rats were } \\
\text { randomly distributed into six groups } \\
\text { according to the following treatments: }(1) \\
\text { Control; (2) Glucose; (3) Glucose+NAM } \\
0.06 \% ; \text { (4) Glucose+NAM } 0.12 \% ;(5) \\
\text { Fructose; and (6) Fructose+NAM } 0.12 \% \text {. }\end{array}$ & $\begin{array}{l}\text { NAM attenuates increases in levels of FFA, thiobarbituric acid reactive } \\
\text { substances, and markers of hepatic damage induced by high glucose or } \\
\text { fructose. NAM decreases hepatic steatosis. NAM only partially prevented } \\
\text { changes in the glutathione/glutathione disulfide levels and redox potential, } \\
\text { as well as pro-inflammatory conditions. NAM mitigates increases in } \\
\text { hepatic glucose-6-phosphate dehydrogenase mRNA, protein levels, and } \\
\text { specific activity induced by glucose or fructose. }\end{array}$ & Mejia et al. [72] \\
\hline NAM & $\begin{array}{l}\text { C57Bl/6J transgenic mice overexpressing } \\
\text { NNMT vs. wild type, HFD + water } \\
\text { containing } 1 \% \text { NAM }\end{array}$ & $\begin{array}{l}\text { NNMT overactivation decreases the NAD content in the liver and } \\
\text { decreases gene activity related to fatty acid oxidation by inhibiting SIRT3 } \\
\text { and fibrosis by reducing the tissue NAD content and methylation pool. }\end{array}$ & $\begin{array}{c}\text { Komatsu et al. } \\
\text { [73] }\end{array}$ \\
\hline
\end{tabular}


Table 3. NAD supplementation for NAFLD treatment.

\begin{tabular}{|c|c|c|c|}
\hline Treatment & Study design & Results & ref \\
\hline NR & C57Bl/6J, HFD vs. control diet. & $\begin{array}{c}\text { Long-term NR administration in vivo lowers HFD-induced body weight gain } \\
\text { by enhancing energy expenditure, and ameliorates insulin-sensitivity and } \\
\text { cholesterol profiles. }\end{array}$ & Canto et al. [70] \\
\hline NR & $\begin{array}{l}\text { Dominant negative (DN)-NAMPT } \\
\text { transgenic C57BL/6J, HFD vs. control } \\
\text { diet. }\end{array}$ & $\begin{array}{l}\text { DN-NAMPT mice under control diet displays systemic NAD reduction and } \\
\text { had moderate NAFLD phenotypes, including lipid accumulation, enhanced } \\
\text { oxidative stress, triggered inflammation, and impaired insulin sensitivity in } \\
\text { liver. All these NAFLD phenotypes deteriorate further under HFD challenge. } \\
\text { Oral administration of NR completely corrects these NAFLD phenotypes } \\
\text { induced by NAD deficiency alone or with HFD. }\end{array}$ & Zhou et al. [50] \\
\hline NR & $\begin{array}{l}\text { C57BL/6JRcc mice, semi-synthetic } \\
\text { obesogenic diet containing } 0.14 \% \\
\text { L-tryptophan and either } 5,15,30,180 \text {, or } \\
\quad 900 \mathrm{mg} \text { NR per kg diet }\end{array}$ & $\begin{array}{c}\text { There is a dose-response effect to NR; in particular, mice fed a } 30 \mathrm{mg} \mathrm{NR} / \mathrm{kg} \\
\text { diet are more metabolically flexible than the wide range of other NR } \\
\text { concentrations. Moreover, in epididymal white adipose tissue, the gene } \\
\text { expression of Peroxisome-proliferator-activated receptor- } \gamma \text { (Ppar- } \gamma \text { ), } \\
\text { Superoxide dismutase-2 (SOD2) and Peroxiredoxin } 3 \text { (Prdx3) - are significantly } \\
\text { upregulated in mice fed } 30 \mathrm{mg} \mathrm{NR/kg.}\end{array}$ & Shi et al. [80] \\
\hline NR & $\begin{array}{l}\text { Obese-diabetic KK/HlJ mice, control or } \\
\text { NR group }\end{array}$ & $\begin{array}{l}\text { Total cholesterol concentration in the liver, glucose control, and levels of } \\
\text { serum insulin and adiponectin are improved by NR. At liver histology, NR } \\
\text { rescues the disrupted cellular integrity of the mitochondria and nucleus of } \\
\text { obese-diabetic KK mice. In addition, NR treatment significantly improves } \\
\text { hepatic pro-inflammatory markers, including tumor necrosis factor-alpha, } \\
\text { Interleukin (IL) 6, and IL-1. These results demonstrate that NR attenuates } \\
\text { hepatic metaflammation by modulating the NLRP3 inflammasome. }\end{array}$ & Lee et al. [81] \\
\hline NR & C57BL/6J, HFD vs. control diet & $\begin{array}{c}\text { NR improves glucose tolerance, and reduces weight gain, liver damage, and } \\
\text { hepatic steatosis. }\end{array}$ & $\begin{array}{l}\text { Trammell et al. } \\
\text { [82] }\end{array}$ \\
\hline MNAM & C57BL/6J, HFD vs. control diet & $\begin{array}{l}\text { MNAM significantly lowers liver and serum cholesterol and TG levels, while } \\
\text { also suppressing fatty acid and cholesterol synthesis and the expression of } \\
\text { lipogenic and cholesterol synthesis genes. MNAM-supplemented mice have } \\
\text { higher liver SIRT1 protein expression. Consistent with higher SIRT1 protein } \\
\text { expression, liver FoxO1 acetylation is significantly lower. MNAM-fed mice } \\
\text { had significantly lower liver expression of the pro-inflammatory cytokines. }\end{array}$ & Hong et al. [58] \\
\hline
\end{tabular}


Table 3. Cont

\begin{tabular}{|c|c|c|c|}
\hline Treatment & Study design & Results & ref \\
\hline $\begin{array}{l}\text { Flavonoid } \\
\text { Apigenin (CD38 } \\
\text { inihibitor) }\end{array}$ & C57BL/6, HFD vs. control diet & $\begin{array}{l}\text { Apigenin inhibits CD38 and is associated with increased NAD and decreased } \\
\text { protein acetylation, likely through the activation of SIRT1. Apigenin improves } \\
\text { glucose homeostasis in vivo and promotes fatty acid oxidation in the liver. }\end{array}$ & Escande et al. [86] \\
\hline PARP-1 inhibitors & $\begin{array}{l}\text { HeLa cells exposed to the } \\
\text { PARP-1-activating agent } \\
\text { N-methyl-N'-nitro-N-nitrosoguanidine } \\
\text { (MNNG) or to PARP-1 inhibitors after } \\
\text { MNNG exposure. }\end{array}$ & $\begin{array}{l}\text { PARP-1 hyperactivity in the nucleus rapidly impairs ATP production in } \\
\text { mitochondria, whereas the release of the pro-apoptotic factors AIF/Cyt-c from } \\
\text { mitochondria only occurs several hours after PARP-1 hyperactivation. PARP-1 } \\
\text { inhibitors are able to prevent MNNG-induced nucleotide depletion, } \\
\text { apoptosis-inducing factor (AIF) release, and cell death. }\end{array}$ & Cipriani et al. [87] \\
\hline $\begin{array}{l}\text { Rucaparib (PARP1 } \\
\text { inhibitor) }\end{array}$ & $\begin{array}{l}\text { PARP1 wild-type }(\mathrm{WT}) \text { and PARP1 } \\
\text { knock-out }(\mathrm{KO}) \text { mice }\end{array}$ & $\begin{array}{c}\text { In PARP1 WT livers, the NAD concentration in the rucaparib-treated group } \\
\text { was significantly higher when compared with the concentration in untreated } \\
\text { mice, and similar to the concentration in KO mice. }\end{array}$ & Almeida et al. [88] \\
\hline $\begin{array}{l}\text { TES-991 (ACMS } \\
\text { decarboxylase } \\
\text { inhibitor) }\end{array}$ & $\begin{array}{l}\text { C57BL/6J under methionine-choline } \\
\text { deficient (MCD) diet }\end{array}$ & $\begin{array}{l}\text { Supplementing the MCD diet with TES-991 increases hepatic NAD, attenuates } \\
\text { hepatic steatosis and plasma transaminases levels, protects against hepatic } \\
\text { lipid accumulation, attenuates inflammation, recovers hepatic SOD2 activity } \\
\text { and ATP content, and reverses NAFLD changes in the transcription of genes } \\
\text { involved in ROS defense, } \beta \text {-oxidation, inflammation, and mitochondrial } \\
\text { function. }\end{array}$ & $\begin{array}{l}\text { Katsyuba et al. } \\
{[14]}\end{array}$ \\
\hline
\end{tabular}

NR, nicotinamide riboside; MNAM, N1-methyl nicotinamide; PARP1, poly (ADP ribose) polymerase 1; HFD, high fat diet. 


\title{
7. Conclusions
}

Until now, there is still no approved drug for the treatment of NAFLD, and although lifestyle modification appears beneficial in patients with NAFLD, no single approach is likely to be suitable for all patients. NAD reduction might be caused by the imbalance in NAD biosynthesis and depletion, both of which occur in NAFLD. NAD reduction may induce NAFLD through decreased SIRT activities in the nucleus and mitochondria. The supplementation of key NAD intermediates, such as NMN and NR, can ameliorate NAFLD.

Author Contributions: Conceptualization, J.-F.D. and M.G.; Literature Analysis, M.G.; Writing-Original Draft Preparation, M.G. and J.-F.D.; Writing-Review and Editing, M.G. and J.-F.D.

Funding: J.F.D is supported by the Swiss National Foundation (310030-185219).

Conflicts of Interest: JF Dufour: Advisory committee for Abbvie, Bayer, BMS, Fallk, Genfit, Genkyotex, Gilead, Heparegenerix, Intercept, Lilly, Merck, Novartis. M Guarino has no conflicts of interest to declare.

\begin{abstract}
Abbreviations
ACC, acetyl-CoA carboxylase; ACMS, amino- $\beta$-carboxymuconate- $\varepsilon$-semialdehyde; ACS, acetyl-CoA synthetase; ADPR, ADP ribose; AMPK, AMP-activated protein kinase; DNL, de novo lipogenesis; eNAMPT, extracellular NAMPT; FAS, fatty acid synthase; FFA, free fatty acid; HCC, hepatocellular carcinoma; HFD, high fat diet; iNAMPT, intracellular NAMPT; KO, knock-out; MNAM, N1-methyl nicotinamide; NA, nicotinic acid; NAD, nicotinamide adenine dinucleotide; NADP, phosphorylated nicotinamide adenine dinucleotide; NAFLD, nonalcoholic fatty liver disease; NAM, nicotinamide; NAMN, NA mononucleotide; NAMPT, nicotinamide phosphoribosyltransferase; NAPRT1, nicotinate phosphoribosyltransferase domain containing 1; NASH, non-alcoholic steatohepatitis; NMN, nicotinamide mononucleotide; NMNAT, nicotinamide nucleotide adenylyltransferase 3; NNMT, nicotinamide-N-methyltransferase; NR, nicotinamide riboside; NRK, NR kinase; PARP, poly (ADP ribose) polymerase; ROS, reactive oxygen species; SIRT, sirtuin; SREBP1, sterol regulatory element-binding protein 1; TNF- $\alpha$, tumor necrosis factor- $\alpha$; WT, wild-type.
\end{abstract}

\section{References}

1. Kalra, S. Diabesity. J. Pak. Med. Assoc. 2013, 63, 532-534.

2. Musso, G.; Gambino, R.; De Michieli, F.; Cassader, M.; Rizzetto, M.; Durazzo, M.; Fagà, E.; Silli, B.; Pagano, G. Dietary habits and their relations to insulin resistance and postprandial lipemia in nonalcoholic steatohepatitis. Hepatology 2003, 37, 909-916. [CrossRef]

3. Sookoian, S.; Burgueno, A.L.; Castano, G.; Pirola, C.J. Should nonalcoholic fatty liver disease be included in the definition of metabolic syndrome? A cross-sectional comparison with adult treatment panel III criteria in nonobese nondiabetic subjects: Response to Musso. Diabetes Care 2008, 31, e42. [CrossRef]

4. Kawano, Y.; Cohen, D.E. Mechanisms of hepatic triglyceride accumulation in non-alcoholic fatty liver disease. J. Gastroenterol. 2013, 48, 434-441. [CrossRef]

5. Koo, S.H. Nonalcoholic fatty liver disease: Molecular mechanisms for the hepatic steatosis. Clin. Mol. Hepatol. 2013, 19, 210-215. [CrossRef]

6. Jiang, Z.G.; Tapper, E.B.; Connelly, M.A.; Pimentel, C.F.; Feldbrügge, L.; Kim, M.; Krawczyk, S.; Afdhal, N.; Robson, S.C.; Herman, M.A.; et al. Steatohepatitis and liver fibrosis are predicted by the characteristics of very low density lipoprotein in nonalcoholic fatty liver disease. Liver Int. 2016, 36, 1213-1220. [CrossRef]

7. Sherriff, J.L.; O'Sullivan, T.A.; Properzi, C.; Oddo, J.L.; Adams, L.A. Choline, its potential role in nonalcoholic fatty liver disease, and the case for human and bacterial genes. Adv. Nutr. 2016, 7, 5-13. [CrossRef]

8. Buzzetti, E.; Pinzani, M.; Tsochatzis, E.A. The multiple-hit pathogenesis of non-alcoholic fatty liver disease (NAFLD). Metabolism 2016, 65, 1038-1048. [CrossRef]

9. Canto, C.; Auwerx, J. NAD ${ }^{+}$as a signaling molecule modulating metabolism. Cold Spring Harb. Symp. Quant. Biol. 2011, 76, 291-298. [CrossRef]

10. Barbosa, M.T.; Soares, S.M.; Novak, C.M.; Sinclair, D.; Levine, J.A.; Aksoy, P.; Chini, E.N. The enzyme CD38 (a NAD glycohydrolase, EC 3.2.2.5) is necessary for the development of diet-induced obesity. FASEB J. 2007, 21, 3629-3639. [CrossRef]

11. Bai, P.; Cantó, C.; Oudart, H.; Brunyánszki, A.; Cen, Y.; Thomas, C.; Yamamoto, H.; Huber, A.; Kiss, B.; Houtkooper, R.H.; et al. PARP-1 inhibition increases mitochondrial metabolism through SIRT1 activation. Cell Metab. 2011, 13, 461-468. [CrossRef] 
12. Yoshino, J.; Mills, K.F.; Yoon, M.J.; Imai, S.I. Nicotinamide mononucleotide, ia key NAD(+) intermediate, treats the pathophysiology of diet- and age-induced diabetes in mice. Cell Metab. 2011, 14, 528-536. [CrossRef]

13. Mouchiroud, L.; Houtkooper, R.H.; Auwerx, J. NAD ${ }^{+}$metabolism: A therapeutic target for age-related metabolic disease. Crit. Rev. Biochem. Mol. Biol. 2013, 48, 397-408. [CrossRef]

14. Katsyuba, E.; Mottis, A.; Zietak, M.; De Franco, F.; van der Velpen, V.; Gariani, K.; Ryu, D.; Cialabrini, L.; Matilainen, O.; Liscio, P.; et al. De novo $\mathrm{NAD}^{+}$synthesis enhances mitochondrial function and improves health. Nature 2018, 563, 354-359. [CrossRef]

15. Bogan, K.L.; Brenner, C. Nicotinic acid, nicotinamide, and nicotinamide riboside: A molecular evaluation of $\mathrm{NAD}^{+}$precursor vitamins in human nutrition. Annu. Rev. Nutr. 2008, 28, 115-130. [CrossRef]

16. Samal, B.; Sun, Y.; Stearns, G.; Xie, C.; Suggs, S.; McNiece, I. Cloning and characterization of the cDNA encoding a novel human pre-B-cell colony enhancing factor. Mol. Cell Biol. 1994, 14, 1431-1437. [CrossRef]

17. Rongvaux, A.; Shea, R.J.; Mulks, M.H.; Gigot, D.; Urbain, J.; Leo, O.; Andris, F. Pre-B cell colony-enhancing factor, whose expression is up-regulated in activated lymphocytes, is a nicotinamide phosphoribosyltransferase, a cytosolic enzyme involved in NAD biosynthesis. Eur. J. Immunol. 2002, 32, 3225-3234. [CrossRef]

18. Tanaka, M.; Nozaki, M.; Fukuhara, A.; Segawa, K.; Aoki, N.; Matsuda, M.; Komuro, R.; Shimomura, I. Visfatin is released from 3T3-L1 adipocytes via a non-classical pathway. Biochem. Biophys. Res. Commun. 2007, 359, 194-201. [CrossRef]

19. Garten, A.; Petzold, S.; Barnikol-Oettler, A.; Körner, A.; Thasler, W.E.; Kratzsch, J.; Kiess, W.; Gebhardt, R. Nicotinamide phosphoribosyltransferase (NAMPT/PBEF/visfatin) is constitutively released from human hepatocytes. Biochem. Biophys. Res. Commun. 2010, 391, 376-381. [CrossRef]

20. Friebe, D.; Neef, M.; Kratzsch, J.; Erbs, S.; Dittrich, K.; Garten, A.; Petzold-Quinque, S.; Blüher, S.; Reinehr, T.; Stumvoll, M.; et al. Leucocytes are a major source of circulating nicotinamide phosphoribosyl transferase (NAMPT)/pre-B cell colony (PBEF)/visfatin linking obesity and inflammation in humans. Diabetologia 2011, 54, 1200-1211. [CrossRef]

21. Yang, H.; Lavu, S.; Sinclair, D.A. Nampt/PBEF/Visfatin: A regulator of mammalian health and longevity? Exp. Gerontol. 2006, 41, 718-726. [CrossRef] [PubMed]

22. Revollo, J.R.; Körner, A.; Mills, K.F.; Satoh, A.; Wang, T.; Garten, A.; Dasgupta, B.; Sasaki, Y.; Wolberger, C.; Townsend, R.R.; et al. Nampt/PBEF/Visfatin regulates insulin secretion in beta cells as a systemic NAD biosynthetic enzyme. Cell Metab. 2007, 6, 363-375. [CrossRef] [PubMed]

23. Yang, H.; Yang, T.; Baur, J.A.; Perez, E.; Matsui, T.; Carmona, J.J.; Lamming, D.W.; Souza-Pinto, N.C.; Bohr, V.A.; Rosenzweig, A.; et al. Nutrient-sensitive mitochondrial NAD ${ }^{+}$levels dictate cell survival. Cell 2007, 130, 1095-1107. [CrossRef] [PubMed]

24. Bowlby, S.C.; Thomas, M.J.; D’Agostino, R.B., Jr.; Kridel, S.J. Nicotinamide phosphoribosyl transferase (Nampt) is required for de novo lipogenesis in tumor cells. PLoS ONE 2012, 7, e40195. [CrossRef] [PubMed]

25. Pillai, J.B.; Isbatan, A.; Imai, S.; Gupta, M.P. Poly(ADP-ribose) polymerase 1 dependent cardiac myocyte cell death during heart failure is mediated by $\mathrm{NAD}^{+}$depletion and reduced Sir2 $\alpha$ deacetylase activity. J. Biol. Chem. 2005, 280, 43121-43130. [CrossRef]

26. Rodgers, J.T.; Lerin, C.; Gerhart-Hines, Z.; Puigserver, P. Metabolic adaptations through the PGC $1 \alpha$ and SIRT1 pathways. FEBS Lett. 2008, 582, 46-53. [CrossRef]

27. Luo, X.; Kraus, W.L. On PAR with PARP: Cellular stress signaling through poly (ADP-ribose) and PARP 1. Genes Dev. 2012, 26, 417-432. [CrossRef]

28. Kraus, D.; Yang, Q.; Kong, D.; Banks, A.S.; Zhang, L.; Rodgers, J.T.; Pirinen, E.; Pulinilkunnil, T.C.; Gong, F.; Wang, Y.C.; et al. Nicotinamide Nmethyltransferase knockdown protects against diet-induced obesity. Nature 2014, 508, 258-262. [CrossRef]

29. Kannt, A.; Pfenninger, A.; Teichert, L.; Tönjes, A.; Dietrich, A.; Schön, M.R.; Klöting, N.; Blüher, M. Association of nicotinamide-N-methyltransferase mRNA expression in human adipose tissue and the plasma concentration of its product, 1-methylnicotinamide, with insulin resistance. Diabetologia 2015, 58, 799-808. [CrossRef]

30. Giuliante, R.; Sartini, D.; Bacchetti, T.; Rocchetti, R.; Klöting, I.; Polidori, C.; Ferretti, G.; Emanuelli, M. Potential involvement of nicotinamide n-methyltransferase in the pathogenesis of metabolic syndrome. Metab. Syndr. Relat. Disord. 2015, 13, 165-170. [CrossRef] 
31. Imai, S.; Armstrong, C.M.; Kaeberlein, M.; Guarente, L. Transcriptional silencing and longevity protein Sir2 is an NAD-dependent histone, deacetylase. Nature 2000, 403, 795-800. [CrossRef] [PubMed]

32. Pfluger, P.T.; Herranz, D.; Velasco-Miguel, S.; Serrano, M.; Tschöp, M.H. Sirt1 protects against high-fat diet-induced metabolic damage. Proc. Natl. Acad. Sci. USA 2008, 105, 9793-9798. [CrossRef] [PubMed]

33. Houtkooper, R.H.; Pirinen, E.; Auwerx, J. Sirtuins as regulators of metabolism and healthspan. Nat. Rev. Mol. Cell Biol. 2012, 13, 225-238. [CrossRef] [PubMed]

34. Caron, A.Z.; He, X.; Mottawea, W.; Seifert, E.L.; Jardine, K.; Dewar-Darch, D.; Cron, G.O.; Harper, M.E.; Stintzi, A.; McBurney, M.W. The SIRT1 deacetylase protects mice against the symptoms of metabolic syndrome. FASEB J. 2014, 28, 1306-1316. [CrossRef] [PubMed]

35. Asher, G.; Gatfield, D.; Stratmann, M.; Reinke, H.; Dibner, C.; Kreppel, F.; Mostoslavsky, R.; Alt, F.W.; Schibler, U. SIRT1 regulates circadian clock gene expression through PER2 deacetylation. Cell 2008, 134, 317-328. [CrossRef] [PubMed]

36. Nakahata, Y.; Kaluzova, M.; Grimaldi, B.; Sahar, S.; Hirayama, J.; Chen, D.; Guarente, L.P.; Sassone-Corsi, P. The NAD ${ }^{+}$-dependent deacetylase SIRT1 modulates CLOCK-mediated chromatin remodeling and circadian control. Cell 2008, 134, 329-340. [CrossRef] [PubMed]

37. Imai, S. "Clocks" in the NAD World: NAD as a metabolic oscillator for the regulation of metabolism and aging. Biochim. Biophys. Acta 2010, 1804, 1584-1590. [CrossRef] [PubMed]

38. Peek, C.B.; Affinati, A.H.; Ramsey, K.M.; Kuo, H.Y.; Yu, W.; Sena, L.A.; Ilkayeva, O.; Marcheva, B.; Kobayashi, Y.; Omura, C.; et al. Circadian clock NAD ${ }^{+}$cycle drives mitochondrial oxidative metabolism in mice. Science 2013, 342, 1243417. [CrossRef]

39. Fulco, M.; Schiltz, R.L.; Iezzi, S.; King, M.T.; Zhao, P.; Kashiwaya, Y.; Hoffman, E.; Veech, R.L.; Sartorelli, V. Sir2 regulates skeletal muscle differentiation as a potential sensor of the redox state. Mol. Cell 2003, 12, 51-62. [CrossRef]

40. Kendrick, A.A.; Choudhury, M.; Rahman, S.M.; McCurdy, C.E.; Friederich, M.; Van Hove, J.L.; Watson, P.A.; Birdsey, N.; Bao, J.; Gius, D.; et al. Fatty liver is associated with reduced SIRT3 activity and mitochondrial protein hyperacetylation. Biochem. J. 2011, 433, 505-514. [CrossRef]

41. Ishikawa, S.; Li, G.; Takemitsu, H.; Fujiwara, M.; Mori, N.; Yamamoto, I.; Arai, T. Change in mRNA expression of sirtuin 1 and sirtuin 3 in cats fed on high fat diet. BMC Vet. Res. 2013, 9, 187. [CrossRef] [PubMed]

42. Shen, C.; Dou, X.; Ma, Y.; Ma, W.; Li, S.; Song, Z. Nicotinamide protects hepatocytes against palmitate-induced lipotoxicity via SIRT1-dependent autophagy induction. Nutr. Res. 2017, 40, 40-47. [CrossRef] [PubMed]

43. Lin, S.-J.; Ford, E.; Haigis, M.; Liszt, G.; Guarente, L. Calorie restriction extends yeast life span by lowering the level of NADH. Genes Dev. 2004, 18, 12-16. [CrossRef] [PubMed]

44. Zhang, H.; Ryu, D.; Wu, Y.; Gariani, K.; Wang, X.; Luan, P.; D'Amico, D.; Ropelle, E.R.; Lutolf, M.P.; Aebersold, R.; et al. NAD ${ }^{+}$repletion improves mitochondrial and stem cell function and enhances life span in mice. Science 2016, 352, 1436-1443. [CrossRef] [PubMed]

45. Satoh, A.; Stein, L.; Imai, S. The role of mammalian sirtuins in the regulation of metabolism, aging, and longevity. Handb. Exp. Pharmacol. 2011, 206, 125-162. [CrossRef]

46. Von Schönfels, W.; Patsenker, E.; Fahrner, R.; Itzel, T.; Hinrichsen, H.; Brosch, M.; Erhart, W.; Gruodyte, A.; Vollnberg, B.; Richter, K.; et al. Metabolomic tissue signature in human non-alcoholic fatty liver disease identifies protective candidate metabolites. Liver Int. 2015, 35, 207-214. [CrossRef] [PubMed]

47. Mukherjee, S.; Chellappa, K.; Moffitt, A.; Ndungu, J.; Dellinger, R.W.; Davis, J.G.; Agarwal, B.; Baur, J.A. Nicotinamide adenine dinucleotide biosynthesis promotes liver regeneration. Hepatology 2017, 65, 616-630. [CrossRef]

48. Shi, L.; Tu, B.P. Acetyl-CoA and the regulation of metabolism: Mechanisms and consequences. Curr. Opin. Cell Biol. 2015, 33, 125-131. [CrossRef]

49. Penke, M.; Larsen, P.S.; Schuster, S.; Dall, M.; Jensen, B.A.; Gorski, T.; Meusel, A.; Richter, S.; Vienberg, S.G.; Treebak, J.T.; et al. Hepatic NAD salvage pathway is enhanced in mice on a high-fat diet. Mol. Cell Endocrinol. 2015, 412, 65-72. [CrossRef]

50. Zhou, C.C.; Yang, X.; Hua, X.; Liu, J.; Fan, M.B.; Li, G.Q.; Song, J.; Xu, T.Y.; Li, Z.Y.; Guan, Y.F.; et al. Hepatic $\mathrm{NAD}(+)$ deficiency as a therapeutic target for non-alcoholic fatty liver disease in ageing. Br. J. Pharmacol. 2016, 173, 2352-2368. [CrossRef] 
51. Chang, Y.H.; Chang, D.M.; Lin, K.C.; Shin, S.J.; Lee, Y.J. Visfatin in overweight/obesity, type 2 diabetes mellitus, insulin resistance, metabolic syndrome and cardiovascular diseases: A meta-analysis and systemic review. Diabetes Metab. Res. Rev. 2011, 27, 515-527. [CrossRef] [PubMed]

52. Dahl, T.B.; Yndestad, A.; Skjelland, M.; Oie, E.; Dahl, A.; Michelsen, A.; Damas, J.K.; Tunheim, S.H.; Ueland, T.; Smith, C.; et al. Increased expression of visfatin in macrophages of human unstable carotid and coronary atherosclerosis: Possible role in inflammation and plaque, destabilization. Circulation 2007, 115, 972-980. [CrossRef] [PubMed]

53. El-Mesallamy, H.O.; Kassem, D.H.; El-Demerdash, E.; Amin, A.I. Vaspin and visfatin/Nampt are interesting interrelated adipokines playing a role in the pathogenesis of type 2 diabetes mellitus. Metabolism 2011, 60, 63-70. [CrossRef] [PubMed]

54. Aller, R.; de Luis, D.A.; Izaola, O.; Sagrado, M.G.; Conde, R.; Velasco, M.C.; Alvarez, T.; Pacheco, D.; Gonzalez, J.M. Influence of visfatin on histopathological changes of non-alcoholic fatty liver disease. Dig. Dis. Sci. 2009, 54, 1772-1777. [CrossRef] [PubMed]

55. Lee, J.J.; Lambert, J.E.; Hovhannisyan, Y.; Ramos-Roman, M.A.; Trombold, J.R.; Wagner, D.A.; Parks, E.J. Palmitoleic acid is elevated in fatty liver disease and reflects hepatic lipogenesis. Am. J. Clin. Nutr. 2015, 101, 34-43. [CrossRef] [PubMed]

56. Berlanga, A.; Guiu-Jurado, E.; Porras, J.A.; Auguet, T. Molecular pathways in non-alcoholic fatty liver disease. Clin. Exp. Gastroenterol. 2014, 7, 221-239. [CrossRef]

57. Hallows, W.C.; Lee, S.; Denu, J.M. Sirtuins deacetylate and activate mammalian acetyl-CoA synthetases. Proc. Natl. Acad. Sci. USA 2006, 103, 10230-10235. [CrossRef]

58. Hong, S.; Moreno-Navarrete, J.M.; Wei, X.; Kikukawa, Y.; Tzameli, I.; Prasad, D.; Lee, Y.; Asara, J.M.; Fernandez-Real, J.M.; Maratos-Flier, E.; et al. Nicotinamide N-methyltransferase regulates hepatic nutrient metabolism through Sirt1 protein stabilization. Nat. Med. 2015, 21, 887-894. [CrossRef]

59. Kennedy, A.R.; Pissios, P.; Otu, H.; Roberson, R.; Xue, B.; Asakura, K.; Furukawa, N.; Marino, F.E.; Liu, F.F.; Kahn, B.B.; et al. A high-fat, ketogenic diet induces a unique metabolic state in mice. Am. J. Physiol. 2007, 292, E1724-E1739. [CrossRef]

60. Bordone, L.; Cohen, D.; Robinson, A.; Motta, M.C.; van Veen, E.; Czopik, A.; Steele, A.D.; Crowe, H.; Marmor, S.; Luo, J.; et al. SIRT1 transgenic mice show phenotypes resembling calorie restriction. Aging Cell 2007, 6, 759-767. [CrossRef]

61. Sazci, A.; Ozel, M.D.; Ergul, E.; Aygun, C. Association of nicotinamide-N-methyltransferase gene rs694539 variant with patients with nonalcoholic steatohepatitis. Genet. Test. Mol. Biomark. 2013, 17, 849-853. [CrossRef] [PubMed]

62. Hasan, E.M.; Abd Al Aziz, R.A.; Sabry, D.; Darweesh, S.K.; Badary, H.A.; Elsharkawy, A.; Abouelkhair, M.M.; Yosry, A. Genetic Variants in nicotinamide-N-methyltransferase (NNMT) gene are related to the stage of non-alcoholic fatty liver disease diagnosed by controlled attenuation parameter (CAP)-fibroscan. J. Gastrointest. Liver Dis. 2018, 27, 265-272. [CrossRef]

63. Castera, L.; Friedrich-Rust, M.; Loomba, R. Noninvasive Assessment of Liver Disease in Patients with NAFLD. Gastroenterology 2019, 156, 1264-1281.e4. [CrossRef] [PubMed]

64. Gaddipati, R.; Sasikala, M.; Padaki, N.; Mukherjee, R.M.; Sekaran, A.; Jayaraj-Mansard, M.; Rabella, P.; Rao-Guduru, V.; Reddy-Duvvuru, N. Visceral adipose tissue visfatin in nonalcoholic fatty liver disease. Ann. Hepatol. 2010, 9, 266-270. [CrossRef]

65. Auguet, T.; Terra, X.; Porras, J.A.; Orellana-Gavaldà, J.M.; Martinez, S.; Aguilar, C.; Lucas, A.; Pellitero, S.; Hernández, M.; Del Castillo, D.; et al. Plasma visfatin levels and gene expression in morbidly obese women with associated fatty liver disease. Clin. Biochem. 2013, 46, 202-208. [CrossRef] [PubMed]

66. Dahl, T.B.; Haukeland, J.W.; Yndestad, A.; Ranheim, T.; Gladhaug, I.P.; Damås, J.K.; Haaland, T.; Løberg, E.M.; Arntsen, B.; Birkeland, K.; et al. Intracellular nicotinamide phosphoribosyl transferase protects against hepatocyte apoptosis and is down-regulated in nonalcoholic fatty liver disease. J. Clin. Endocrinol. Metab. 2010, 95, 3039-3047. [CrossRef] [PubMed]

67. Kukla, M.; Ciupińska-Kajor, M.; Kajor, M.; Wyleżoł, M.; Zwirska-Korczala, K.; Hartleb, M.; Berdowska, A.; Mazur, W. Liver visfatin expression in morbidly obese patients with nonalcoholic fatty liver disease undergoing bariatric surgery. Pol. J. Pathol. 2010, 61, 147-153. [PubMed] 
68. Amirkalali, B.; Sohrabi, M.R.; Esrafily, A.; Jalali, M.; Gholami, A.; Hosseinzadeh, P.; Keyvani, H.; Shidfar, F.; Zamani, F. Association between Nicotinamide Phosphoribosyltransferase and de novo Lipogenesis in Nonalcoholic Fatty Liver Disease. Med. Princ. Pract. 2017, 26, 251-257. [CrossRef]

69. Tao, R.; Wei, D.; Gao, H.; Liu, Y.; DePinho, R.A.; Dong, X.C. Hepatic FoxOs regulate lipid metabolism via modulation of expression of the nicotinamide phosphoribosyltransferase gene. J. Biol. Chem. 2011, 286, 14681-14690. [CrossRef]

70. Canto, C.; Houtkooper, R.H.; Pirinen, E.; Youn, D.Y.; Oosterveer, M.H.; Cen, Y.; Fernandez-Marcos, P.J.; Yamamoto, H.; Andreux, P.A.; Cettour-Rose, P.; et al. The NAD(+) precursor nicotinamide riboside enhances oxidative metabolism and protects against high-fat diet-induced obesity. Cell Metab. 2012, 15, 838-847. [CrossRef]

71. Gariani, K.; Menzies, K.J.; Ryu, D.; Wegner, C.J.; Wang, X.; Ropelle, E.R.; Moullan, N.; Zhang, H.; Perino, A.; Lemos, V.; et al. Eliciting the mitochondrial unfolded protein response by nicotinamide adenine dinucleotide repletion reverses fatty liver disease in mice. Hepatology 2016, 63, 1190-1204. [CrossRef] [PubMed]

72. Mejía, S.Á.; Gutman, L.A.B.; Camarillo, C.O.; Navarro, R.M.; Becerra, M.C.S.; Santana, L.D.; Cruz, M.; Pérez, E.H.; Flores, M.D. Nicotinamide prevents sweet beverage-induced hepatic steatosis in rats by regulating the G6PD, NADPH/NADP ${ }^{+}$and GSH/GSSG ratios and reducing oxidative and inflammatory, stress. Eur. J. Pharmacol. 2018, 818, 499-507. [CrossRef] [PubMed]

73. Komatsu, M.; Kanda, T.; Urai, H.; Kurokochi, A.; Kitahama, R.; Shigaki, S.; Ono, T.; Yukioka, H.; Hasegawa, K.; Tokuyama, H.; et al. NNMT activation can contribute to the development of fatty liver disease by modulating the NAD ${ }^{+}$metabolism. Sci. Rep. 2018, 8, 8637. [CrossRef] [PubMed]

74. Houtkooper, R.H.; Canto, C.; Wanders, R.J.; Auwerx, J. The secret life of NAD ${ }^{+}$: An old metabolite controlling new metabolic signaling pathways. Endocr. Rev. 2010, 31, 194-223. [CrossRef] [PubMed]

75. Knip, M.; Douek, I.F.; Moore, W.P.; Gillmor, H.A.; McLean, A.E.; Bingley, P.J.; Gale, E.A.; European Nicotinamide Diabetes Intervention Trial Group. Safety of high-dose nicotinamide: A review. Diabetologia 2000, 43, 1337-1345. [CrossRef] [PubMed]

76. Lukasova, M.; Hanson, J.; Tunaru, S.; Offermanns, S. Nicotinic acid (niacin): New lipid independent mechanisms of action and therapeutic potentials. Trends Pharmacol. Sci. 2011, 32, 700-707. [CrossRef] [PubMed]

77. Yadav, R.; France, M.; Younis, N.; Hama, S.; Ammori, B.J.; Kwok, S.; Soran, H. Extended release niacin with laropiprant: A review on efficacy, clinical effectiveness and safety. Expert Opin. Pharmacother. 2012, 13, 1345-1362. [CrossRef] [PubMed]

78. Gomes, A.L.; Teijeiro, A.; Burén, S.; Tummala, K.S.; Yilmaz, M.; Waisman, A.; Theurillat, J.P.; Perna, C.; Djouder, N. Metabolic Inflammation-Associated IL-17A Causes Non-alcoholic Steatohepatitis and Hepatocellular Carcinoma. Cancer Cell 2016, 30, 161-175. [CrossRef]

79. Trammell, S.A.; Schmidt, M.S.; Weidemann, B.J.; Redpath, P.; Jaksch, F.; Dellinger, R.W.; Li, Z.; Abel, E.D.; Migaud, M.E.; Brenner, C. Nicotinamide riboside is uniquely and orally bioavailable in mice and humans. Nat. Commun. 2016, 7, 12948. [CrossRef] [PubMed]

80. Shi, W.; Hegeman, M.A.; van Dartel, D.A.; Tang, J.; Suarez, M.; Swarts, H.; van der Hee, B.; Arola, L.; Keijer, J. Effects of a wide range of dietary nicotinamide riboside (NR) concentrations on metabolic flexibility and white adipose tissue (WAT) of mice fed a mildly obesogenic diet. Mol. Nutr. Food Res. 2017, 61. [CrossRef]

81. Lee, H.J.; Hong, Y.S.; Jun, W.; Yang, S.J. Nicotinamide riboside ameliorates hepatic metaflammation by modulating NLRP3 inflammasome in a rodent model of type 2 diabetes. J. Med. Food 2015, 18, 1207-1213. [CrossRef] [PubMed]

82. Trammell, S.A.; Weidemann, B.J.; Chadda, A.; Yorek, M.S.; Holmes, A.; Coppey, L.J.; Obrosov, A.; Kardon, R.H.; Yorek, M.A.; Brenner, C. Nicotinamide Riboside Opposes Type 2 Diabetes and Neuropathy in Mice. Sci. Rep. 2016, 6, 26933. [CrossRef] [PubMed]

83. De Picciotto, N.E.; Gano, L.B.; Johnson, L.C.; Martens, C.R.; Sindler, A.L.; Mills, K.F.; Imai, S.; Seals, D.R. Nicotinamide mononucleotide supplementation reverses vascular dysfunction and oxidative stress with aging in mice. Aging Cell 2016, 15, 522-530. [CrossRef] [PubMed]

84. Wang, X.; Hu, X.; Yang, Y.; Takata, T.; Sakurai, T. Nicotinamide mononucleotide protects against beta-amyloid oligomer-induced cognitive impairment and neuronal death. Brain Res. 2016, 1643, 1-9. [CrossRef] [PubMed]

85. Aksoy, P.; White, T.A.; Thompson, M.; Chini, E.N. Regulation of intracellular levels of NAD: A novel role for CD38. Biochem. Biophys. Res. Commun. 2006, 345, 1386-1392. [CrossRef] 
86. Escande, C.; Nin, V.; Price, N.L.; Capellini, V.; Gomes, A.P.; Barbosa, M.T.; O’Neil, L.; White, T.A.; Sinclair, D.A.; Chini, E.N. Flavonoid apigenin is an inhibitor of the NAD ${ }^{+}$ase CD38: Implications for cellular $\mathrm{NAD}^{+}$metabolism, protein acetylation, and treatment of metabolic syndrome. Diabetes 2013, 62, 1084-1109. [CrossRef]

87. Cipriani, G.; Rapizzi, E.; Vannacci, A.; Rizzuto, R.; Moroni, F.; Chiarugi, A. Nuclear poly(ADP-ribose) polymerase-1 rapidly triggers mitochondrial dysfunction. J. Biol. Chem. 2005, 280, 17227-17234. [CrossRef]

88. Almeida, G.S.; Bawn, C.M.; Galler, M.; Wilson, I.; Thomas, H.D.; Kyle, S.; Curtin, N.J.; Newell, D.R.; Maxwell, R.J. PARP inhibitor rucaparib induces changes in NAD levels in cells and liver tissues as assessed by MRS. NMR Biomed. 2017, 30. [CrossRef]

(C) 2019 by the authors. Licensee MDPI, Basel, Switzerland. This article is an open access article distributed under the terms and conditions of the Creative Commons Attribution (CC BY) license (http://creativecommons.org/licenses/by/4.0/). 